\title{
EFFECT OF ASPECT RATIO ON FIRE RESISTANCE OF HOLLOW CORE CONCRETE FLOORS
}

JEREMY CHANG*, PETER J. MOSS ${ }^{\dagger}$, RAJESH P. DHAKAL ${ }^{\dagger}$ and ANDREW H. BUCHANAN ${ }^{\dagger}$

${ }^{*}$ Holmes Fire \& Safety, PO Box 25355, Victoria St. Christchurch 8144, NZ; ${ }^{\dagger}$ University of Canterbury, Private Bag 4800, Christchurch, New Zealand

Email: jeremy.chang@holmesfire.com, telephone: +64 3 3658855, fax: +64 33658856

Based on the paper published in the Proceedings of the Fifth International Conference on Structures in Fire, Singapore, 2008

Several factors can affect the behaviour of the hollowcore floor slabs in fire. This paper analytically investigates the relationship between the fire resistance of the overall floor system and the floor length to width ratio as well as the type of side supports. The study uses beam grillage and shell elements to model the hollowcore slabs and the topping concrete under the platform of the non-linear finite element program, SAFIR. Different methods to model precast, prestressed concrete hollowcore floor slabs subjected to fire are also investigated. The results show that side supports can enhance the fire performance of hollowcore floor slabs provided that the spacing of the side supports does not greatly exceed the span length.

hollowcore slab, SAFIR, computer simulation, aspect ratio, concrete floor 


\section{Introduction}

Precast, prestressed hollowcore concrete floors are very popular in multi-storey buildings because of their excellent structural performance in ambient conditions, high quality control and low on-site labour costs. Hollowcore concrete floors are designed as one-way slab systems, with the units sitting side-by-side, spanning between supporting walls or beams. Most hollowcore concrete floors have in-situ reinforced concrete topping. Structural behaviour of hollowcore concrete floors is dominated by action parallel to the units and their prestressing strands. Two-way action can sometimes occur in such slab systems, resulting from transverse structural behaviour of the topping concrete, depending on the vertical supports parallel to the hollowcore units [1-4].

The fire resistance of hollowcore concrete slab has not been outlined specifically in Eurocode 2 [5]. However, Eurocode 2 provides separate measures for the fire resistance of flat slabs and solid slabs. The tabulated data in Eurocode 2 relate the fire resistance of a flat slab or of a one way solid slab to the slab thickness and the axis distance of the reinforcements to the surface; they also associate the fire resistance of a two-way solid slab to the aspect ratio which serves as an additional parameter. The British Standard BS EN1168 "Precast Concrete Products Hollow Core Slabs" [6] suggests that the fire resistance of hollowcore concrete floors follows the table for flat slabs which does not include the effect of the vertical supports parallel to the hollowcore units. The New Zealand Standard NZS 3101 "The Design of Concrete Structures" [7], however, suggests the fire resistance of hollowcore concrete floors follows the table for solid slabs, which considers the influence of the two-way effect.

In the tabulated data from Eurocode 2, the fire resistance of a two-way supported slab can be affected by the aspect ratio when the ratio of the longer span to the shorter span is less than 2. Nevertheless, whether the same criteria are appropriate for the hollowcore concrete floor is still unanswered, and to the authors' knowledge, currently there are no such studies available, either numerical or experimental, to justify these criteria.

Since conducting experiments to study the effect of aspect ratio of hollowcore floors is very expensive, and also because previous study [4] has successfully predicted the fire performance of hollowcore concrete floor systems with different 
end and side connections using the non-linear finite element program SAFIR [8], numerical modelling of hollowcore concrete floor systems is carried out to study the effect of aspect ratio on the fire performance of hollowcore concrete slabs.

\section{Modelling of Hollowcore Slabs in SAFIR}

The analytical simulations were carried out using SAFIR, a non-linear finite element analysis program which is able to carry out both structural and thermal analysis, with thermal and mechanical properties from Eurocodes 2 and 3 [5, 9] integrated into the program. Chang et al.[4] have shown that SAFIR can successfully predict the performance of hollowcore floor systems in fire by using a grillage of 3D beam elements to simulate the hollowcore units and a layer of shell elements to represent the topping concrete slab which covers the hollowcore units and connects the hollowcore units to each other and to the surrounding structural members.

In the beam grillages, the longitudinal beams run in the direction of the span and represent the webs and flanges of the hollowcore units. The prestressing effect is considered in the longitudinal beam by SAFIR through calculating the stress equilibrium in the first time step of the structural analysis. The transverse beams in the grillage model the continuity of the top and bottom flanges across each hollowcore unit together with the topping concrete. These transverse beams are to capture the affect of thermal expansion in the transverse direction of each hollowcore unit. In thermal analysis the topping is included in both longitudinal and transverse beams to calculate the thermal gradient correctly, but as the topping is simulated using shell elements in structural analysis, the section representing the topping in beam elements in the thermal analysis is taken as an arbitrary material without strength or stiffness. In the shell elements, the reinforcing bars in the topping slab are simulated as layers of smeared steel section across the shell element with each layer exhibiting a uniaxial behaviour.

This modelling scheme does not consider shear and anchorage failures. As perfect bond between the concrete and the reinforcing steel is assumed for both beam and shell elements, as well as between the topping slab (shell elements) and the hollowcore units, bond failures are also not accounted for. It also does not consider spalling or the vertical tensile stresses in the web of hollowcore units. Nevertheless, the model considers the prestressing effect, the thermal strains as 
well as the mechanical stresses induced by incompatible thermal strains in both lateral and longitudinal directions, and the continuity between the hollowcore units which subsequently allows the model to take account of the effects of the end and side supports. Most importantly, the results from this modelling method showed good agreement with experimental results available in literature [4].

The model developed in the previous study worked well for small subassemblies. However, although the sections representing the topping in the beam elements needed in the thermal analysis (Fig. 1) do not contribute to the performance of the slab, they are modelled as non-load bearing material and still consume a lot of computer resources in the structural analysis. As a result, the model becomes too complicated for SAFIR when analysing subassemblies containing more than 4 parallel hollowcore units. Therefore, a new model is needed in order to study the effect of aspect ratio on the fire performance of hollowcore concrete floor systems.

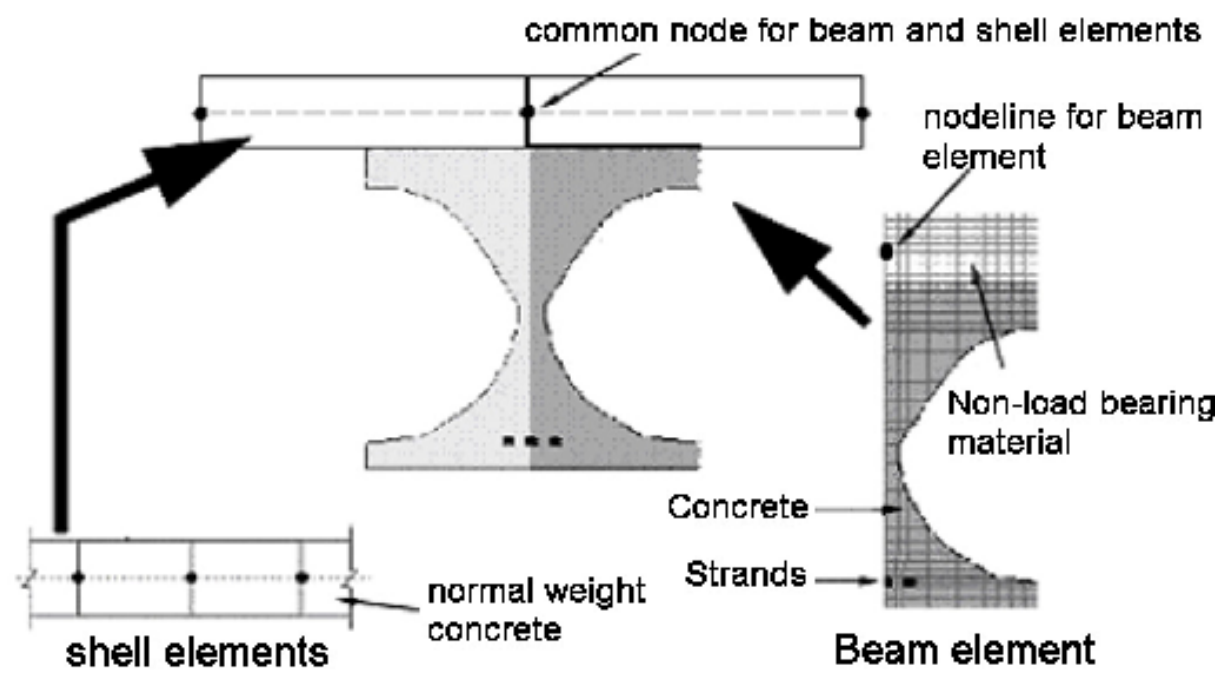

Fig. 1 Discretisation of the cross section of hollowcore unit in the original method

It was found during the development of the original model that, when modelling the floor slab with only one hollowcore unit, simulating the topping slab as part of the beam elements or separately by the shell elements gave the same result [10]. Hence, instead of giving the section representing the topping in the beam elements zero strength and using shell elements to simulate the topping, the topping can be modelled as part of the beam elements and the shell elements can be removed from the model completely. The schematic drawings of the two modelling methods are shown in Fig. 2. This new modelling method need to be validated for 
floors with more than one hollowcore unit, as problems may arise when modelling the topping slab connecting two parallel hollowcore units together.

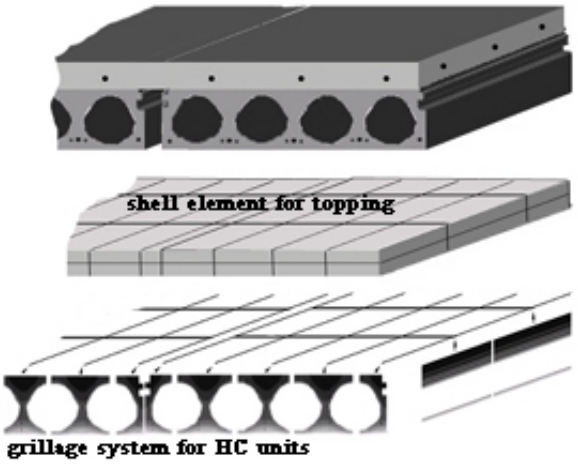

(a)
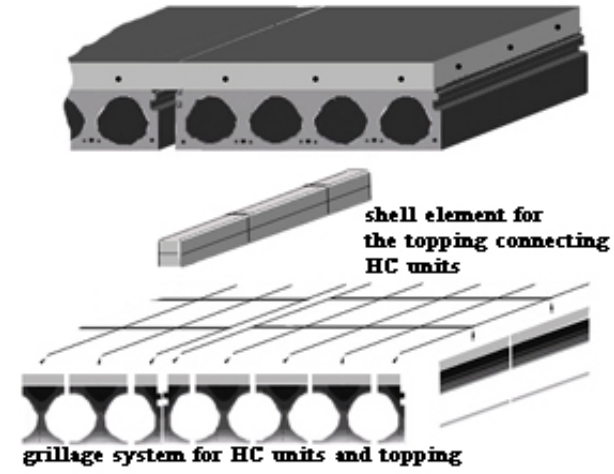

(b)

Fig. 2 Schematic drawing for the (a) original (b) new method to model hollowcore floor systems

\section{Validation of the New Computer Model for Simulating Hollowcore Slabs}

In the first step of the validation, the experimental results of from Universities of Ghent and Liege carried out in 1998 were compared to the simulation results calculated from both the original and new modelling method. Detailed descriptions and the explanations of the designs are given in the test report [11]. The modelled test (Test 1 in the test reports) comprised two independent floor slabs of $2.4 \mathrm{~m}$ width made of two HC units, spanning $3 \mathrm{~m}$ and supported on three beams as shown in Figure 3(a). The floor was made of 200mm hollowcore unit (SP200Ergon) with $50 \mathrm{~mm}$ reinforced topping slab and was exposed to 2 hours of ISO834 standard fire from underneath. A line load of $100 \mathrm{kN}$ was applied at the middle of each of the two spans, which makes the load ratio to be $37 \%$. After two hours of fire exposure, extra load was applied to check the remaining load capacity. Due to symmetry, only half of the floor was simulated (one $1.2 \mathrm{~m}$ wide floor span of 3m) as shown in Fig. 3(b).

In the modelled test, the compressive strength of the concrete in the hollowcore units was $45 \mathrm{MPa}$, and the strand strength was $1.85 \mathrm{GPa}$. The level of prestressing was unspecified in the report and was assumed to be $75 \%$ of the strand strength in the simulations, which is the level usually used in practice. The slab is simulated using both the original method, which has the shell elements representing the topping slab, and the new method, where the topping slab is included in the beam grillage. The end supports of the grillage are assumed to be fixed in the 
simulations, while in the experiment they had a limited freedom for rotation and displacement. The results are shown in Fig. 4. As explained in the previous study, the difference between the simulated results and the actual data is due to the simulation model not being able to predict the shear displacement or failure, as shear effects are not included in the computer software used, and in the experiment shear cracking was observed as early as 7 minutes into the fire test and at the end the slab experienced shear failure. Nevertheless, the focus here is the comparison between the two modelling methods, and it is obvious that the new simulation method provides almost identical results as the original method. This shows that it does not make much difference whether the topping is included in the beam grillage or modelled separately using shell elements in the structural analysis when simulating slabs with one or two hollowcore units and no side supports.

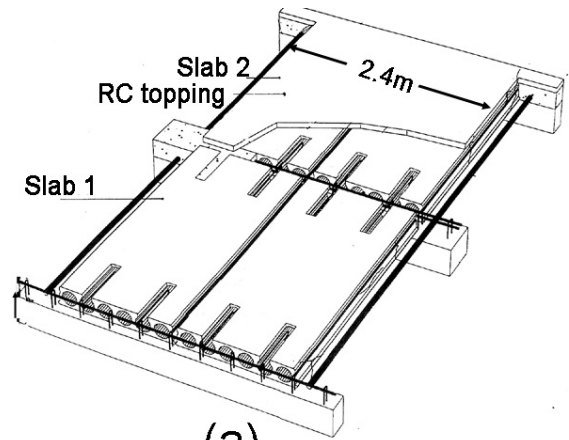

(a)

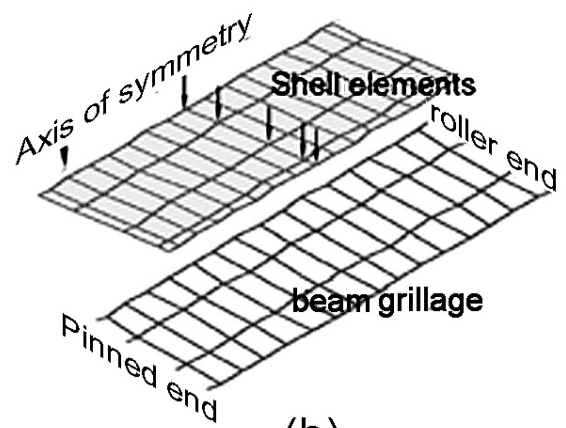

(b)

Fig. 3 (a) Layout (b) illustration of the simulation model using the original method for the test in Universities of Ghent and Liège [11]

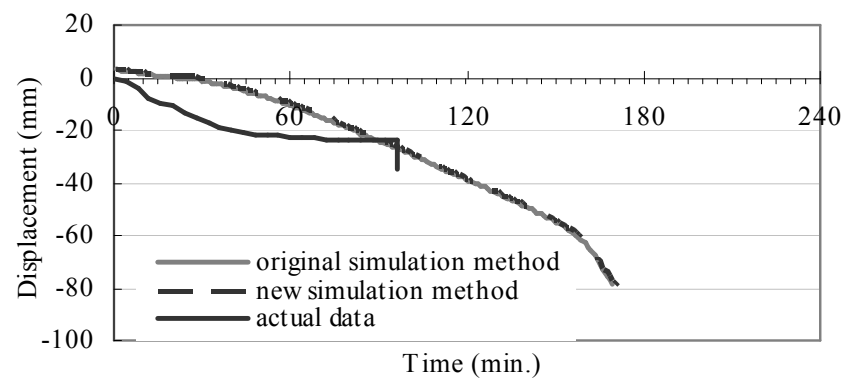

Fig. 4 Comparison of simulation results and actual data from the test in Universities of Ghent and Liège

The second part of the validation process compares the results of simulating previously modelled subassemblies. The structure comprises a floor made from $300 \mathrm{~mm}$ thick hollowcore units (300Dycore) with a $75 \mathrm{~mm}$ reinforced topping. The cross section of the 300Dycore is shown in Fig. 5 and its properties are shown in 
Table 1. The floor is $12.2 \mathrm{~m}$ long and $10.2 \mathrm{~m}$ wide, which includes eight hollowcore units as shown in Fig. 6(a) in the case where the last unit is adjacent to the side beams, or seven units as shown in Fig. 6(b) in the case where there is a concrete infill panel between the last unit and the side beams. The concrete infill panel is suggested in the New Zealand Concrete Standard [7] for seismic resistances. The end and side beams of the structure are $750 \mathrm{~mm}$ deep by $400 \mathrm{~mm}$ wide with three $25 \mathrm{~mm}$ diameter bars at both the top and bottom. The hollowcore units simply sit on the end beams, and the floor is connected to the end and side beams via the topping slab. There are six $3.5 \mathrm{~m}$ high, 750 by $750 \mathrm{~mm}$ square columns in the subassembly spaced $5.1 \mathrm{~m}$ apart along the width of the structure as shown in Fig. 6. The beams are connected to the columns at mid-height. The columns are restrained against displacement at both the top and bottom ends. The slabs and beams were exposed to 3 hours of the ISO 834 standard fire from below, while the columns were fully protected and assumed to remain cool. The applied load on the slab is $8.0 \mathrm{kPa}$, which gives a load ratio in fire of $40 \%$.

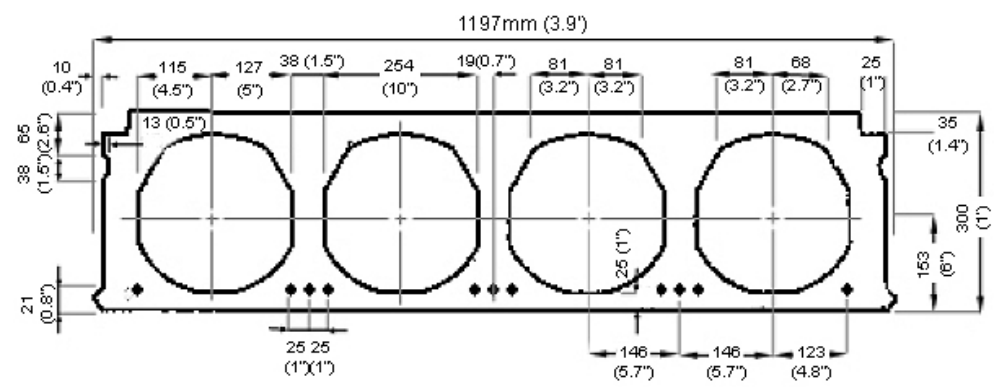

Fig. 5 Cross section of 300Dycore [12]

Table 1 Properties of the hollowcore floor system

\begin{tabular}{|l|l|}
\hline \multicolumn{2}{|l|}{ 300Dycore } \\
\hline Cross sectional area & $0.1606 \mathrm{~m}^{2}$ \\
\hline Self weight & $3.20 \mathrm{kPa}$ \\
\hline Compressive strength & $42 \mathrm{MPa}$ \\
\hline Prestressing strands & Stress relieved 7-wire strand \\
\hline Type & $1.87 \mathrm{GPa}$ \\
\hline Strength & $70 \%$ \\
\hline Prestressing level & $112 \mathrm{~mm}^{2}$ \\
\hline Cross sectional area per strand & \\
\hline Reinforced concrete topping slab & \\
\hline Compressive strength of concrete & $25 \mathrm{MPa}$ \\
\hline Strength of reinforcement & $450 \mathrm{MPa}$ \\
\hline
\end{tabular}




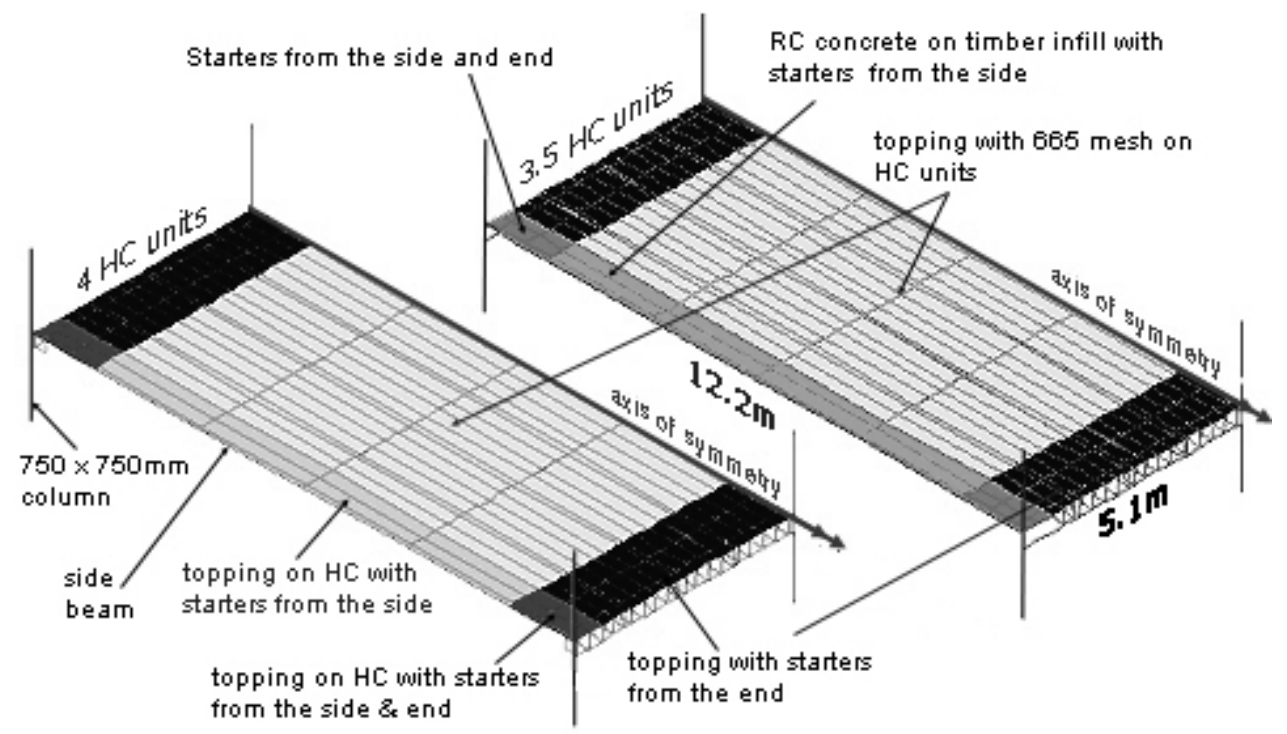

(a) No infill side connection

(b) infill side connection

Fig. 6 Simulation model used in the second step of validation

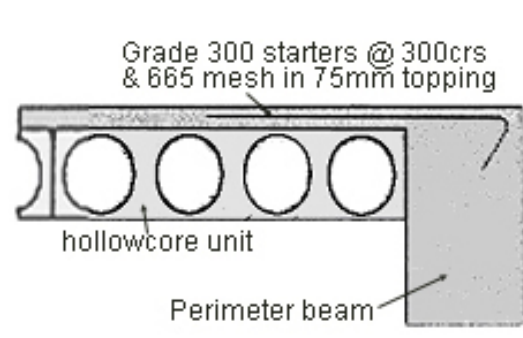

(a)

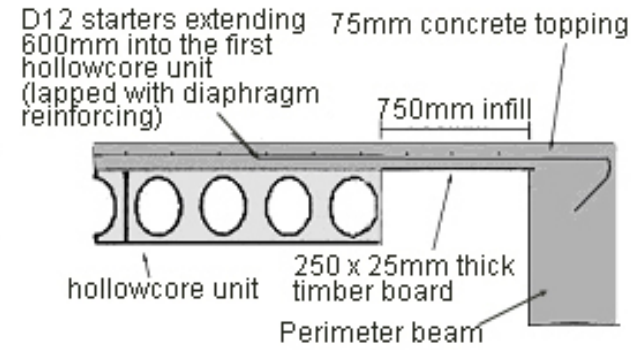

(b)

Fig. 7 Modelled slab-side beam connections (a) without infill (b) with infill

There are three types of side supports considered in this set of validation analyses. The first scenario has no side beams. The other two scenarios with side beams are shown in Fig. 7. The "no infill" side connection scenario (Fig. 7(a)) has the last hollowcore unit immediately adjacent to the side beam. The "infill" side connection scenario (Fig. 7(b)) has a cast-in situ reinforced concrete infill slab between the last hollowcore unit and the side beam to overcome the incompatibility between the displacement of the side beams and the slabs during earthquakes as suggested by NZS3101:2006 [7].

Two simulation methods were examined. The original method (Method I) has the topping slab modelled using a layer of shell elements in the structural analysis (Fig. 2(a)); in Method II the topping slab between the hollowcore units and connecting the hollowcore units to the end beams is modelled using shell elements, but that on top of the hollowcore units is modelled as part of the beam grillage (Fig. 2(b)). Furthermore, the topping slab connecting the hollowcore units 
to the side beam is modelled using shell elements in Method I and beam elements in Method II.

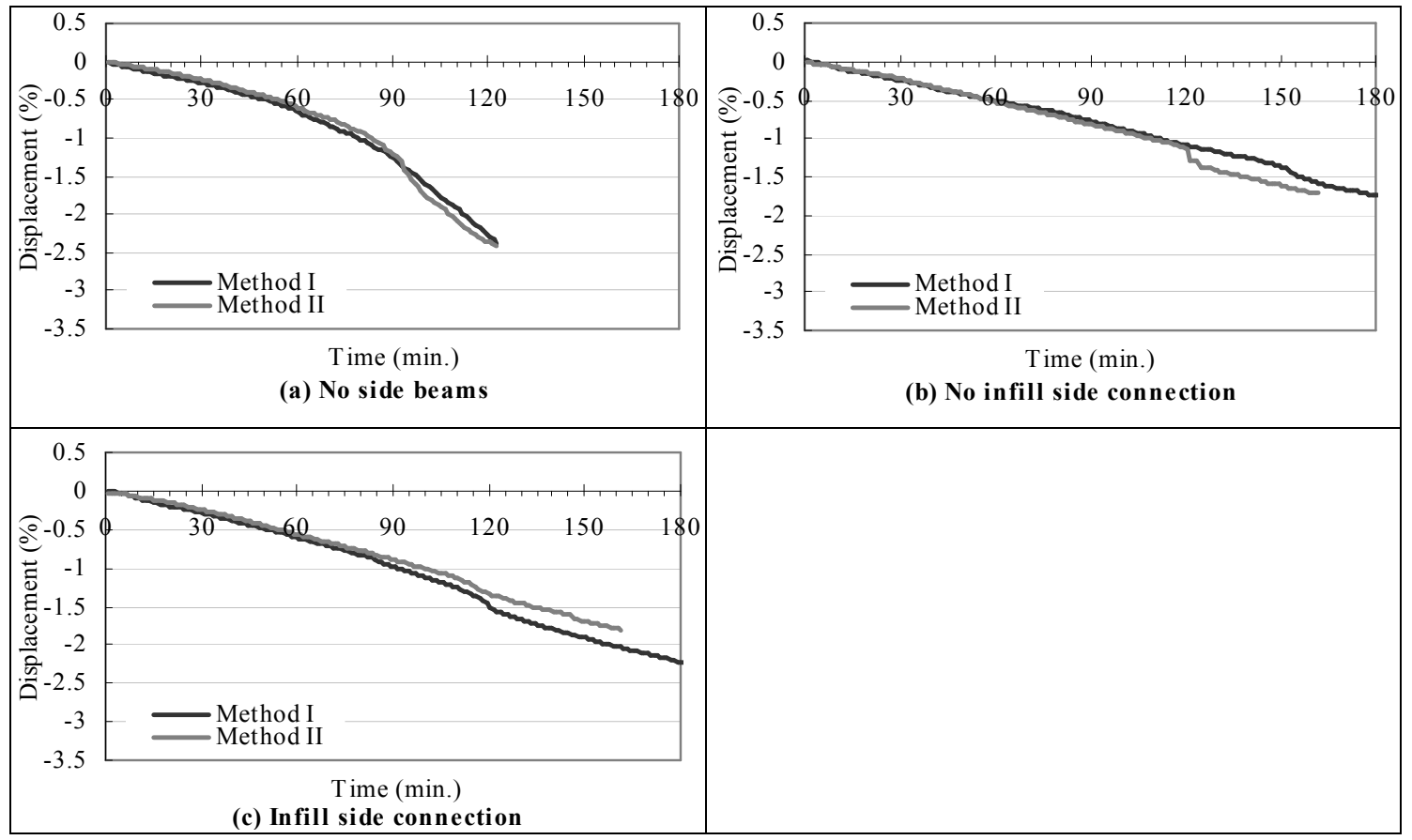

Fig. 8 Comparison of analysis results of a subassembly with different side supports simulated using two different modelling methods (a) with no side beams (b) with side beams but no infill side connection (c) with side beam and infill side connection

The vertical deflections from the two simulation methods at the units closest to the centre, where the maximum deflection occurred, are shown in Fig. 8. The deflections are expressed in relation to the span length. It is evident that the results from the two simulation methods are very similar, and Method II can be used to replace Method I. Because Method II requires fewer computational resources and save simulation time by up to $30 \%$, it should be preferred to model larger structures. The simulations using Method II terminate earlier in the cases with side beams, as in the calculation the stresses are localised in the few remaining shell elements and consequently making stress calculation in the shell elements, especially the ones at the corner, more prone to numerical errors. Nevertheless, because the simulations can be stopped by cracking of shell elements, the stopping time of the simulations does not indicate failure unless supported by other evidence in the output files, such as yielding of the prestressing strands. As the aim of using computer simulations is to carry out virtual ISO 834 standard fire tests on the hollowcore floor systems through analysis, the failure criterion of the slab should be taken as either the collapse of the slab, or the time when the maximum deflection exceeds $1 / 30$ of the span length, as in a standard fire test. 


\section{Effect of Aspect Ratios to the Overall Performance in Fire}

Previous studies have shown that side supports are beneficial to hollowcore concrete floor systems which are normally designed as one-way slabs under cold conditions. To study the extent of the benefit resulting from the side supports, several subassemblies with different floor aspect ratios and three different side support conditions are investigated as shown in Table 2. The subassemblies are the same as those used in the second step of the validation process except the length and width of the floor. The end and side beams as well as the floor were exposed to the ISO fire from underneath, while the columns were assumed to remain cool throughout the fire. The columns are spaced every $5 \mathrm{~m}$ along the width in the cases where the overall width is $5 \mathrm{~m}$ or $10 \mathrm{~m}$, and every $6 \mathrm{~m}$ in the other cases. Fig. 9 shows a typical modelled subassembly.

Table 2 Studied aspect ratios

\begin{tabular}{|l|l|l|l|l|l|}
\hline \multirow{4}{*}{$\begin{array}{l}\text { Comparison } \\
\mathbf{1}\end{array}$} & Span & Width & $\begin{array}{l}\text { Aspect } \\
\text { ratio }\end{array}$ & $\begin{array}{l}\text { FRR as 2-way } \\
\text { solid slab in } \\
\text { Table 5.8, EC2 }\end{array}$ & $\begin{array}{l}\text { FRR as flat } \\
\text { slab in Table } \\
\text { 5.9, EC2 }\end{array}$ \\
\cline { 2 - 7 } & $12 \mathrm{~m}$ & $5 \mathrm{~m}$ & 0.4 & 60 & 60 \\
\cline { 2 - 7 } & $12 \mathrm{~m}$ & $15 \mathrm{~m}$ & 0.8 & 120 & 60 \\
\cline { 2 - 7 } & $12 \mathrm{~m}$ & $20 \mathrm{~m}$ & 1.7 & 90 & 60 \\
\hline \multirow{2}{*}{ Comparison } & $18 \mathrm{~m}$ & $10 \mathrm{~m}$ & 0.6 & 90 & 60 \\
\cline { 2 - 7 } & $15 \mathrm{~m}$ & $10 \mathrm{~m}$ & 0.7 & 120 & 60 \\
\cline { 2 - 7 } & $12 \mathrm{~m}$ & $10 \mathrm{~m}$ & 0.8 & 120 & 60 \\
\cline { 2 - 6 } & $9 \mathrm{~m}$ & $10 \mathrm{~m}$ & 1.1 & 120 & 60 \\
\hline
\end{tabular}




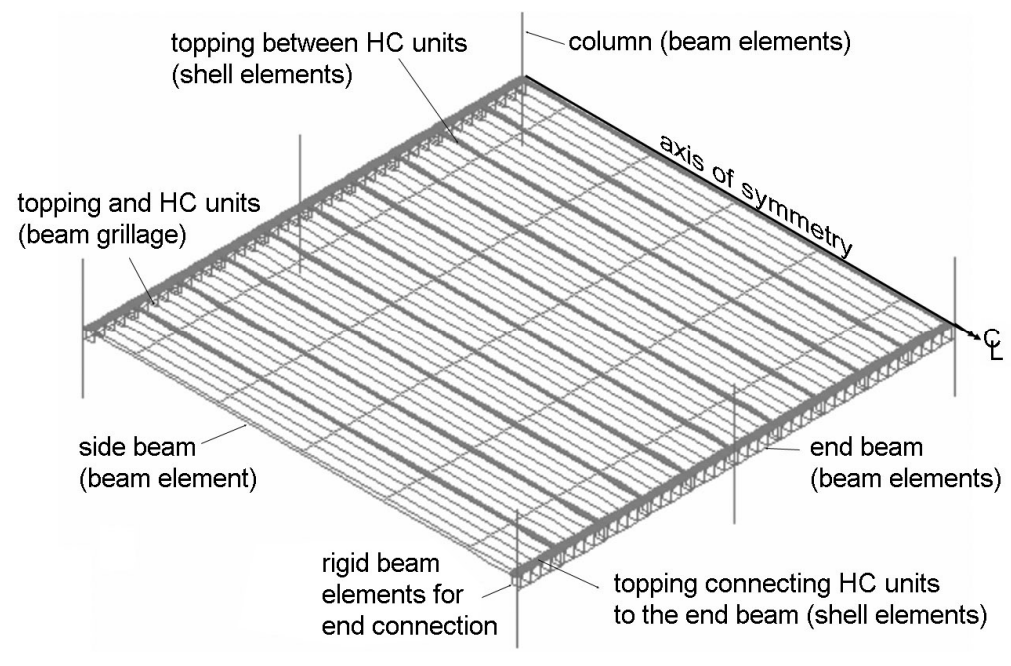

Fig. 9 Simulation model of the $12 \mathrm{~m}$ long $20 \mathrm{~m}$ wide hollowcore floor system with no-infill connection to the side beams

In the tabulated data of Eurocode 2, the benefit of the side supports to a solid slab diminishes when the ratio of the longer side to the shorter side exceeds 1:2, and becomes more significant when the ratio is smaller than 1:1.5. From this study two sets of comparison can be drawn. Comparison 1 fixes the span length to $12 \mathrm{~m}$ and changes the width of the floor to study the affect of the side supports. Comparison 2 fixes the width to $10 \mathrm{~m}$ and varies the span length to compare whether the tabulated data of Eurocode 2 for solid slab is applicable to hollowcore floor systems.

\section{Comparison 1- fixed span length and variable slab width}

Fig. 10 shows the maximum vertical displacement in the slab (at the centre of the slab in the bay farthest from the sides) from Comparison 1, with the deflections expressed as a ratio of the span length. Theoretically, without side beams the width of the subassemblies should not influence the performance of the slab and this is reflected in Fig. 10 (a). Because more elements are included in the model it is more likely for the simulation to encounter numerical errors, which subsequently causes the simulation to stop before reaching failure. Therefore, the simulations for wider slabs stopped earlier than for the $10 \mathrm{~m}$ wide slab. Fig. 10(b) shows that when the side beams are included in the model, and the closer spaced they are, the less deformation the slab is going to encounter. 


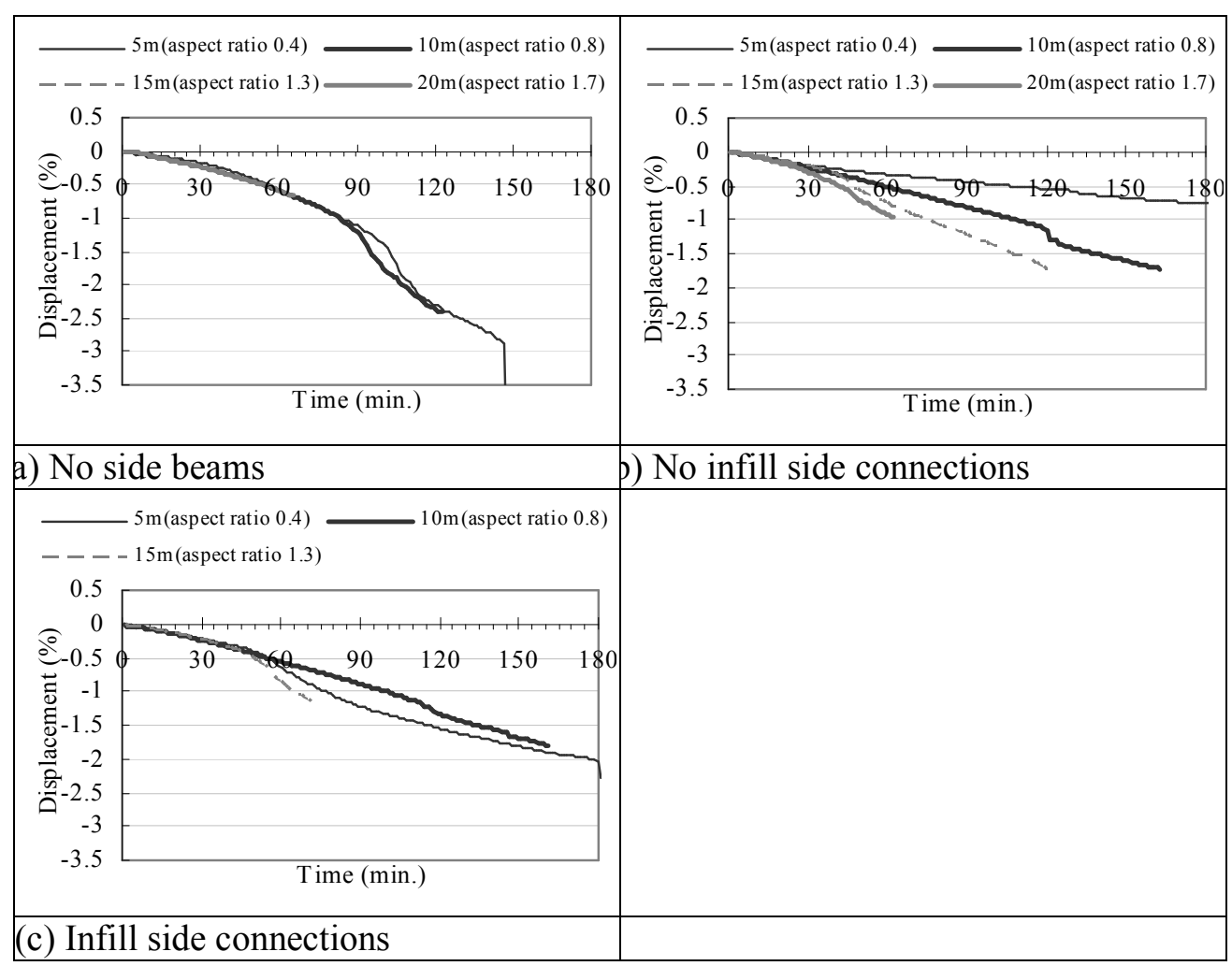

Fig. 10 Maximum vertical displacement in fire of $12 \mathrm{~m}$ span subassemblies and various widths with (a) no side beams (b) side beams, connections with no infill (c) side beams, with infill connection

Comparing Fig. 10(b) to 10(a) shows that the presence of side beams slightly aggravated the deflection in the cases of $15 \mathrm{~m}$ or $20 \mathrm{~m}$ floor width. Fig. 11 shows the shape of the deformed slab in the slab with two side beams $20 \mathrm{~m}$ apart. This difference is due to the presence of the lateral restraint coming from the side beam. This phenomenon is investigated further with a $20 \mathrm{~m}$ wide model with no side beams but with lateral restraint along the sides. This additional model has the same dimensions as the $20 \mathrm{~m}$ floor system without the side beam, however, the sides of the slab is restrained to move along the slab width, but it is still free to deflect vertically and to rotate. This model is similar to a continuous slab in reality where the floor slab at the sides may provide restraint to the lateral movement.

The deflected shapes of the three $12 \mathrm{~m}$ long $20 \mathrm{~m}$ wide slabs with different levels of lateral restraint after 1 hour of fire exposure are shown in Fig. 11. It is apparent that the bowing in each bay of the slab occurs when there are restraints on lateral movement. Fig. 11(d) shows the profile of each slab and demonstrates the difference of the mid-span deflection as well as the lateral displacement at the side in the case without side beams or lateral restraint. 


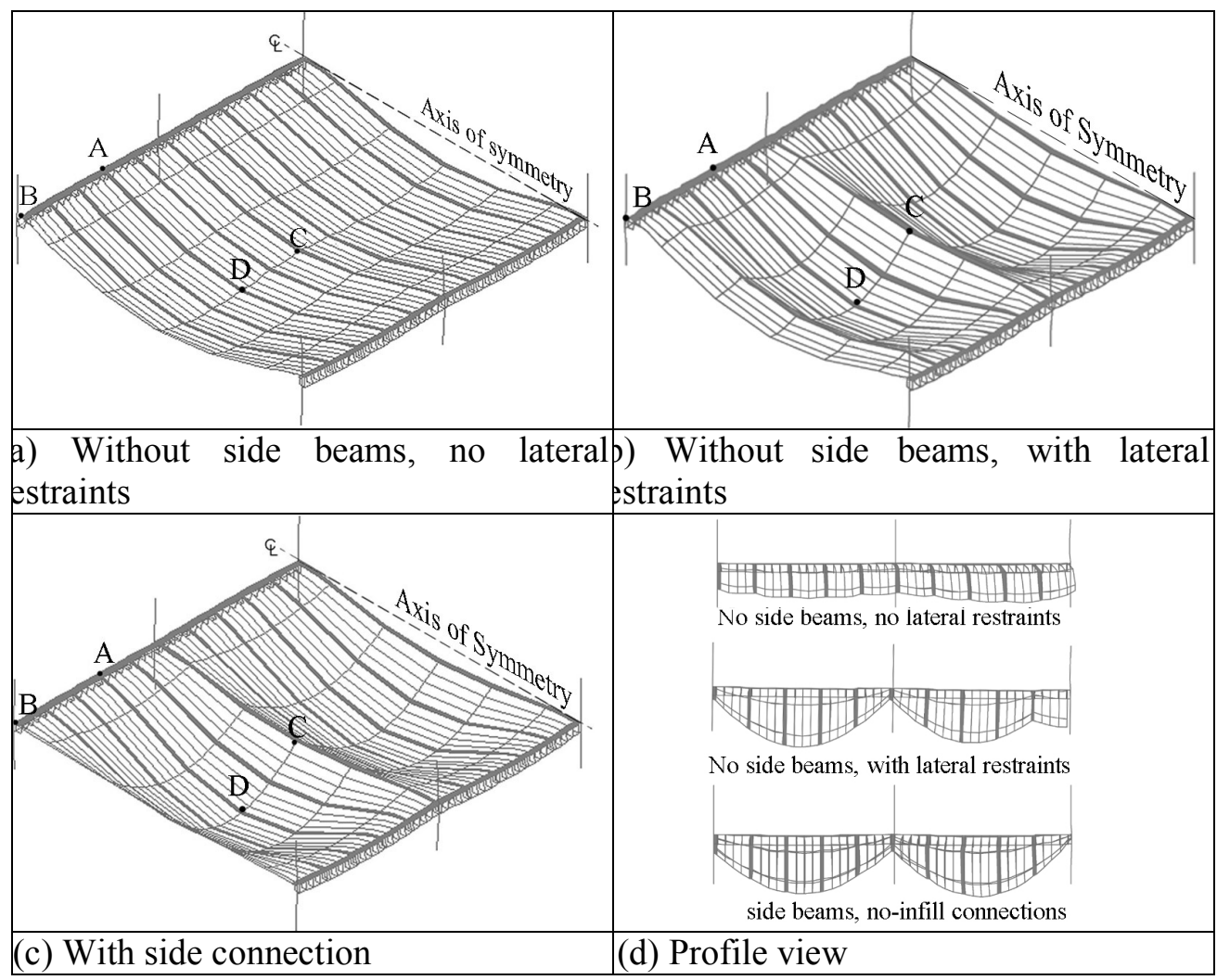

Fig. 11 Deflected shape of the $12 \mathrm{~m}$ long $20 \mathrm{~m}$ wide hollowcore floor system after 1 hour of fire exposure (a) without side beams, no lateral restraints (b) without side beams, with lateral restraints (c) with side connection (d) profile view (deformation exaggerated 20 times)

Fig. 12(a) and (b) show the vertical mid-span displacement directly between the columns and at the centre of each bay, i.e. points $\mathrm{C}$ and $\mathrm{D}$ respectively in Fig. 11, for the three cases presented in Fig. 11. When there are no lateral restraints at the side, the displacement at points $\mathrm{C}$ and D are almost identical. Fig. 12(c) which shows the lateral displacement at the side, where positive is the outward movement. The slab without lateral restraints obviously has lateral movement due to thermal expansion, and the slab with side beam has very small movement due to the restraint coming from the side beam. The vertical displacement trends for the three cases were similar at the first 15 minutes, and afterwards the slabs with lateral restraints start to have greater displacement at point D and upward movement at point $\mathrm{C}$. This shows that the horizontal expansion of the slab starts to become more pronounced at 15 minutes as shown in Fig. 12(c), and the lateral restraints prevent the side of the slab from moving horizontally, therefore the augmented slab width is reflected by the increase in the deflection. It can be seen that the additional restraint from the side beams causes much smaller vertical 
deflections at point $\mathrm{C}$, with the slab briefly rising upwards after about 30 minutes of fire exposure, before increasing again.

The change of the deflection shape across the slab is also reflected in the transverse beam axial force. Fig. 12(d) shows the transverse beam axial force in the hollowcore slab near Point $\mathrm{C}$ in Fig. 11. The transverse beam axial force in the case without lateral restraints is very small in Fig. 12(d) as expected. The lateral restraint, coming from either the side beam or the defined restraint, counter acts with the thermal expansion in the transverse direction and consequently increases the transverse beam axial force, which is shown as the high compression during the first 30 minutes in Fig. 12(d). Afterwards, the increase of the deflections shown in Fig. 12 (a) and (b) reduces the compressive axial force within the slab following P- $\Delta$ Effect. Fig. 12(e) shows that the longitudinal displacements at the ends for the three cases shown in Fig. 11 are almost identical, and the ends have little effect on the difference of the overall deformation shapes.

In the cases with wide slabs, the large curvature near the side beam supports causes a concentration of stress in the shell elements at the corner of the slab, which consequently causes the program to stop. Regardless of the stopping time of the simulation, the results from Comparison 1 show a clear benefit of providing supports parallel to the span direction, with spacing equal to or smaller than the span length. It also shows that providing side supports with spacing greater than the span length has little benefit. 

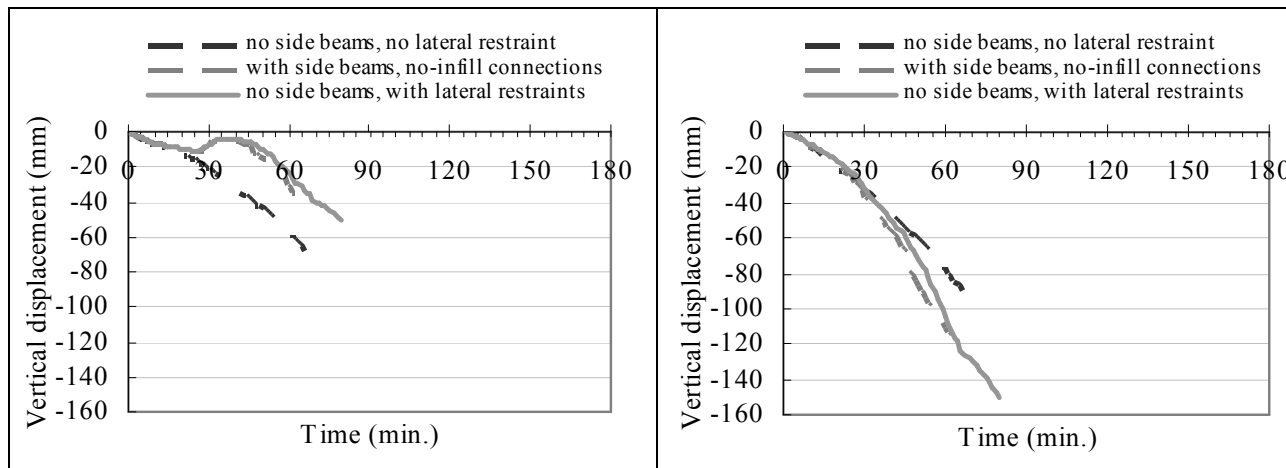

a) Vertical displacement at point $\mathrm{C}$

b) Vertical displacement at point $\mathrm{D}$
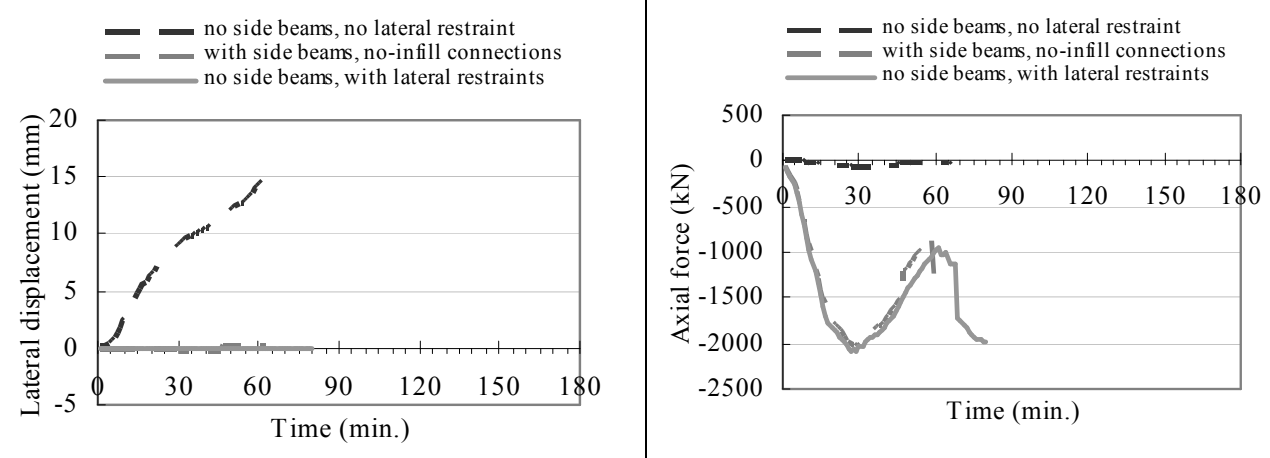

(c) Lateral displacement at the side

d) Transverse beam axial force near point C

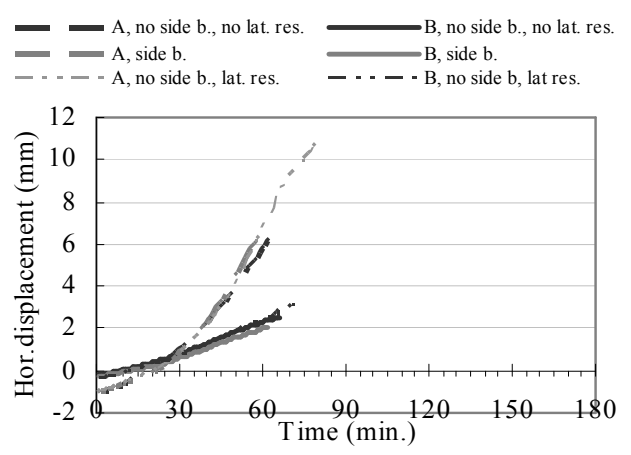

(c) Longitudinal displacements at points A \& B

Fig. 12 Comparison of the $12 \mathrm{~m}$ long $20 \mathrm{~m}$ wide hollowcore floor systems after 1 hour of fire exposure (a) vertical displacement at point $\mathrm{C}$; (b) vertical displacement at point D (c) lateral displacement at the side (d) transverse beam axial force near point $\mathrm{C}$ (e) longitudinal displacements at points A \& B

\section{Comparison 2 - fixed slab width with variable span length}

The results from Comparison 2 are shown in Fig. 13, again with the maximum vertical displacement in the slab expressed as a ratio to the span length. The displacements of the slabs with the infill side connection initially are similar to those with no side beams but became relatively smaller after having further 
exposure to the fire. Nevertheless, they are always greater than those with no-infill side connection. Fig. 13(a) shows excellent performance for all cases. Fig. 13(b) (aspect ratio 1:0.8) shows the side beams giving much smaller deflections than no side beams after 60 minutes fire exposure. Similar results at much shorter times are seen in Fig. 13(c) and (d) for very long spans.

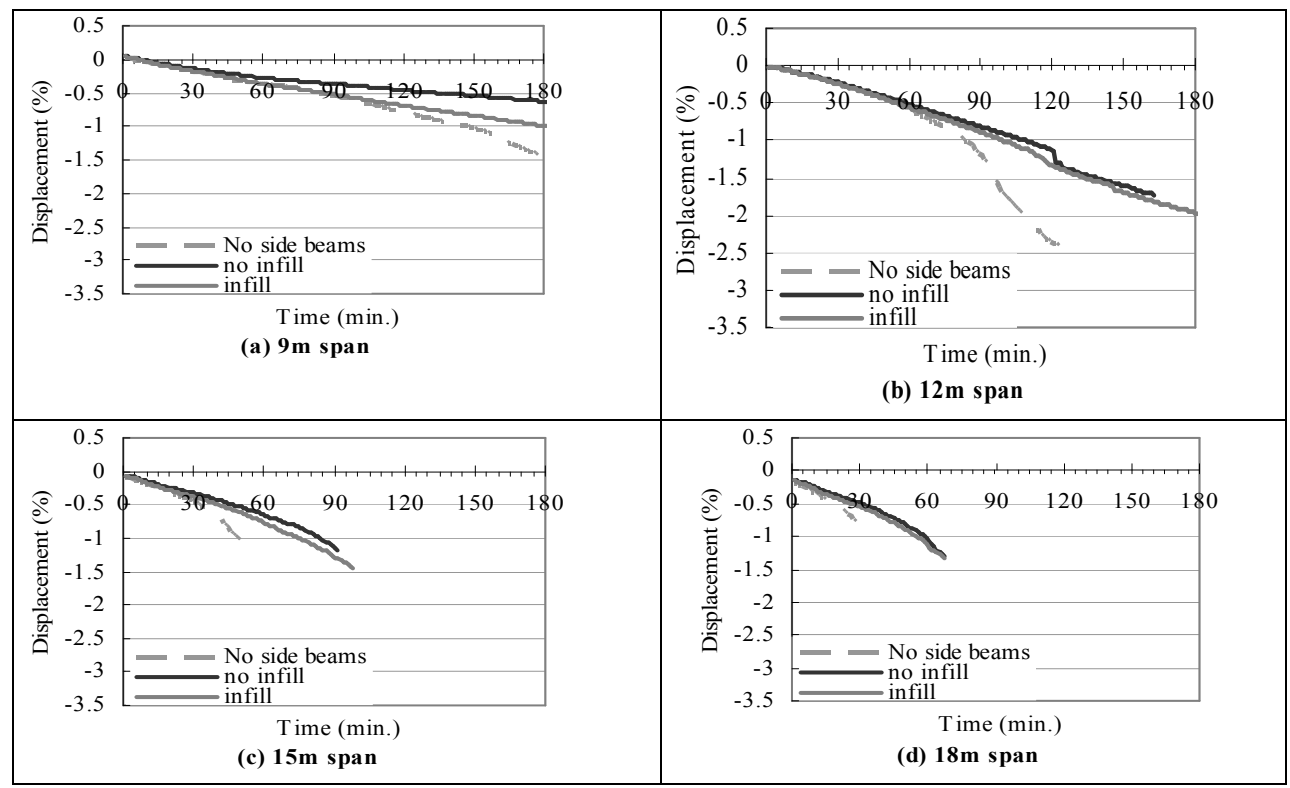

Fig. 13 Maximum displacement at the midspan of the $10 \mathrm{~m}$ wide subassemblies with various span lengths and side supports

Based on all the simulation results presented in this paper and in the previous study, it is shown that the performance of the hollowcore floor systems is dominated by the behaviour along the span. Therefore, it is not suitable for the tabulated data for two-way solid slabs in Eurocode 2 to be applied to hollowcore floor systems. Nevertheless, the simulation results showed the benefit of providing supports parallel to the span direction in fire, and it shows that to use the table for flat slabs in Eurocode 2 and ignore the effect of the vertical supports parallel to the hollowcore units is very conservative. To achieve a better performance of hollowcore floor systems in fire it is suggested to provide some side beams spaced as close as the span length of the units, regardless of the type of connection used between the side beams and the units adjacent to them. Because the hollowcore floor systems are usually designed under ambient conditions as one-way slabs and the side supports are ignored, these extra side beams are mainly to enhance the fire performance and they are also called "fire emergency beams". 


\section{Conclusions}

The performance of hollowcore concrete floor systems in fire depends on several factors. This paper investigates the influence of the width to floor span ratio (i.e. aspect ratio) on the behaviour of the slab in fire. In order to conduct the investigation, a new version of the previously used model was proposed and validated. Unlike the previous model using shell elements to simulate the topping and beam grillage system to simulate the hollowcore units, the new model includes the topping slab as part of the beam grillage system and uses shell elements only for the area of topping slab where there are no hollowcore units underneath. This new model provides very similar results to the original model but requires less computer resources, therefore is more suitable to simulate large and complex structures.

Several subassemblies with different geometries were simulated to investigate the effect of the floor aspect ratio on the structural behaviour in fire. The results show that for hollowcore floor systems it is not suitable to use the tabulated data for the two-way solid slab in Eurocode 2 as the table is too optimistic about the effect of the side supports when the aspect ratio is greater than 1:1.5. Using the table for flat slabs in Eurocode 2 as suggested by BS EN 1168, however, can be very conservative. The results also show that providing side supports such as "fire emergency beams" with spacing equal or less to the span length of the unit can increase the performance of the hollowcore concrete floor systems in fire.

\section{References}

[1] Fellinger, JHH. Shear and Anchorage Behaviour of Fire Exposed Hollowcore Slabs, DUP Science, the Netherlands, 2004

[2] Fib. Résistance au Cisaillement de Dalles Alvéolées Précontraintes, Studiecommmissie SSTC, University of Liège, Belgium, 1998

[3] BEF. Hollow Core Slabs and Fire - Documentation on Shear Capacity, Birch \& Krogboe A/S, Denmark, 2005

[4] Chang, J., Buchanan, AH, Dhakal, RP. \& Moss, PJ, "Hollowcore concrete slab exposed to fire”, Fire and Materials, Online ISSN: 1099-1018, 2008

[5] EC2. Eurocode 2: Design of Concrete Structures. PrEN 1992-1-2: General rules - Structural fire design, Brussels: CEN; 2002.

[6] BSI, Precast Concrete Products - Hollow core Slabs, BS EN1168, British Standards Institution, London, 1995 
[7] SNZ, The Design of Concrete Structures, NZS 3101, Standards New Zealand, Wellington, 2006

[8] Franssen, JM., Kodur, VKR. \& Mason, J. User's Manual for SAFIR2001 Free: A Computer Program for Analysis of Structures at Elevated Temperature Conditions, University of Liège, Belgium, 2002

[9] EC3. Eurocode 3: Design of Steel Structures. PrEN 1993-1-2: General rules - Structural fire design. Brussels: CEN; 2002

[10] Chang J. Computer Simulation of Hollowcore Concrete Floor systems Exposed to Fire. PhD Thesis, Christchurch: University of Canterbury; 2007

[11] fib. Résistance au Cisaillement de Dalles Alvéolées Précontraintes. Belgium: Studiecommissie SSTC; 1998.

[12] Firth Stresscrete \& Stahlton Flooring, Precast Concrete Manual 2007, Firth Stresscrete, Porirua, 2007 